\title{
RIEGO POR AVENIDA EN LADERAS SUBÁRIDAS: EL RÍO GUADALENTÍN EN LORCA
}

\author{
Francisco Calvo García-Tornel \\ Universidad de Murcia
}

\section{RESUMEN}

El regadío con aguas de crecida en ambientes semiáridos proporciona recursos abundantes aunque ocasionales a la agricultura en secano. En el área de Lorca (Murcia) las esporádicas avenidas del río Guadalentín se han conducido desde época muy antigua por una extensa red de cauces para beneficiar el amplio cono de deyección de dicho río, sistema actualmente en proceso de abandono o destrucción. La aportación de sedimentos y la práctica agrícola han generado modificaciones morfológicas, apoyadas también en los intentos para defenderse de inundaciones catastróficas.

Palabras clave: riego, avenida, subárido, río Guadalentín, cono de deyección.

\section{ABSTRACT}

Irrigation with floodwaters in semiarid environments provides abundant although occasional resources to rain-fed agriculture. In Lorca area (Murcia), river Guadalentín random floods have been carried since ancient times through an extensive network of channels to benefit the broad alluvial fan of the river, infrastructures that are currently in process of abandonment or destruction. The contributions of sediment and agricultural practices have generated morphological changes, which also are explained by changes made in order to defend from catastrophic flooding.

Keywords: Irrigation, flood, semiarid, Guadalentín river, alluvial fan.

Hace ya algunos años que se señaló la importancia y los mecanismos del riego por aguas de avenida en laderas subáridas (Morales, 1968), iniciando así un conjunto de estudios centrados en el Sureste peninsular y en buena parte debidos al mismo autor. En este artículo se aborda la caracterización de uno de los 
dispositivos más amplios de este tipo existentes: el instalado sobre el abanico aluvial de Guadalentín en Lorca (Murcia). Por su propia naturaleza, este tradicional modo de aprovechamiento del agua se sitúa en un umbral de difícil equilibrio entre los efectos benéficos de la aportación de caudales a la agricultura y la posibilidad de que el exceso de estos se convierta en inundación catastrófica.

Es por esta razón que el conjunto de infraestructuras establecidas para distribuir las aguas de avenida suelen tener al mismo tiempo el carácter de dispositivo para riego y el de defensa contra la posibilidad de catástrofe. Los caudales de crecida cargados de sedimentos riegan y devuelven fertilidad al suelo, pero el mismo tiempo necesitan estar cuidadosamente administrados para evitar que su exceso destruya sus beneficios.

Al darse la circunstancia de que el regadío lorquino dispone también de caudales permanentes aunque realmente escasos, el sistema de distribución de unos y otros se solapa y confunde con frecuencia. Aquí sin embargo nos referiremos exclusivamente al que en la comarca se denomina «regadío de turbias» y a los cambios que la aportación de caudales no procedentes de las aguas superficiales del Guadalentín han introducido en el sistema de riegos tradicional.

\section{CARACTERÍSTICAS GENERALES DEL SECTOR}

El largo corredor intrabético de dirección NNO-SSE, flanqueado por fallas de igual orientación, ha funcionado durante el Plio-Cuaternario como una fosa tectónica rellenada de una importante aportación aluvial. En su sector más meridional, en los municipios de Lorca y Puerto Lumbreras (Figura 1), el borde noroeste de dicha fosa se muestra muy activo, dando lugar a un acusado perfil disimétrico en el valle, con pendientes muy rápidas en su margen derecha y suaves en la izquierda. A ello también colabora la mayor eficiencia de los cursos torrenciales que provienen de los frentes montañosos de la vertiente izquierda, que han generado a lo largo del Cuaternario abanicos aluviales extensos y de débil pendiente. Se trata de conos de deyección de perfil convexo y amplios sectores de pie que acusan el progresivo hundimiento de la fosa tectónica del Guadalentín (Conesa et al. 1994).

El comportamiento actual de estos depósitos, que parecen encontrarse en una fase de disección, tiende a excavar en las cabeceras de los abanicos y acumular sedimentos en los sectores distales, circunstancia que dificulta o incluso impide su conexión con el nivel de base del Guadalentín.

La cuenca vertiente a la depresión de las ramblas dispuestas en paralelo y que provienen del sector oriental del la sierra de Las Estancias-Torrecilla y occidental de Almenara, presenta mayor masividad en la primera de estas alineaciones, de donde arrancan los principales cursos torrenciales, con amplias cabeceras drenadas por numerosos pequeños cursos de disposición dendrítica. 


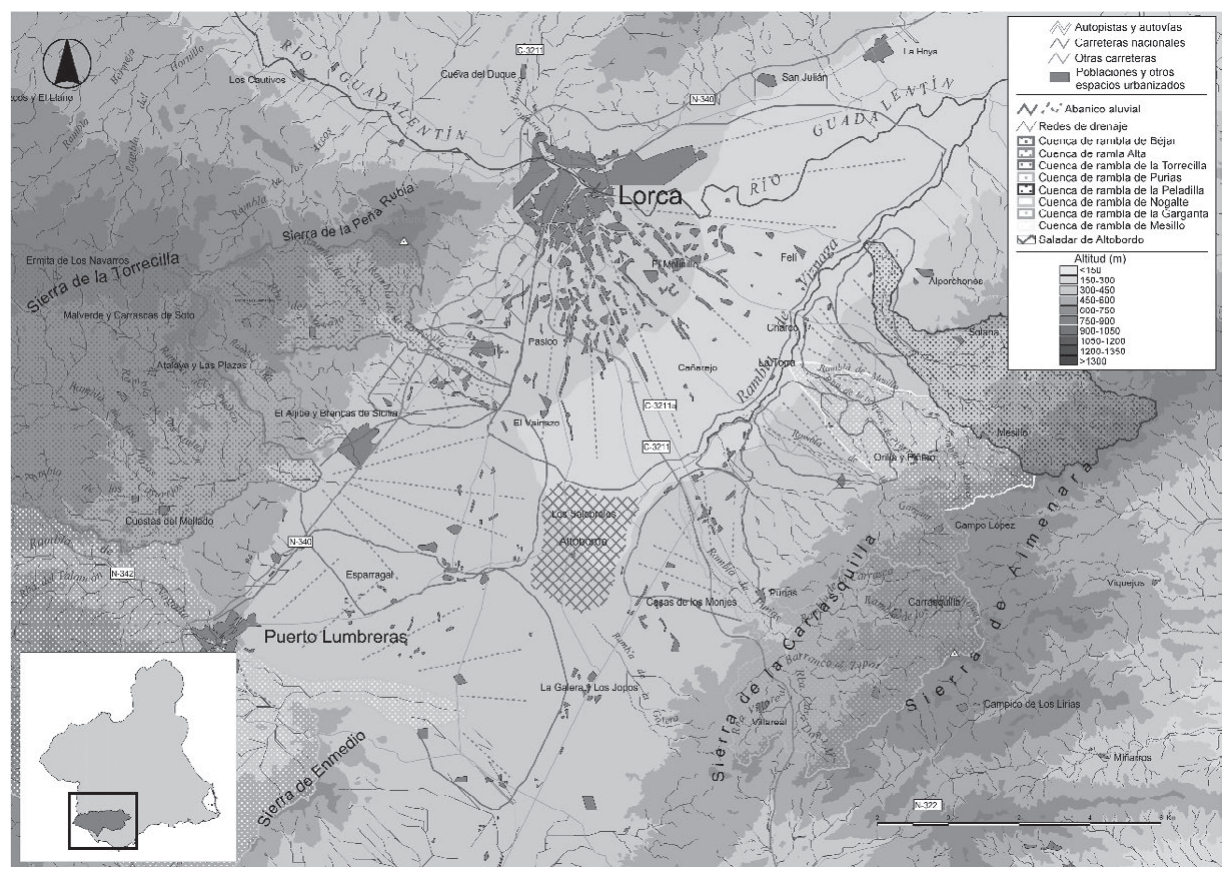

Figura n. ${ }^{\circ}$ 1. El sector meridional de la depresión del Guadalentín. Fuente: Pérez Morales (2008)

De sur a norte destacan las ramblas de Velerda, Nogalte, Béjar, Alta y Torrecilla. En su tramo final, ya en la depresión prelitoral, estos cursos drenan una amplia ladera modelada por conos de deyección y glacis entre los que se pierden los cauces antes de confluir en la rambla de Viznaga, nivel de base local (Navarro, 1991). El flanco oriental de la depresión, con relieves mucho menos masivos, presenta cursos más cortos, también más o menos paralelos y con fuertes pendientes (ramblas de Purias, Garganta, Mesillo y otras) cuyo nivel de base es también la rambla de Viznaga. Este colector, que desagua y confluye hacia el río Guadalentín con un trazado de cauce muy difuso, atraviesa amplios sectores semiendorreicos, debidos en líneas generales a la planitud de la fosa, al carácter limo-arcillosos de los materiales que la tapizan y al obstáculo que representa el gran abanico aluvial del río Guadalentin.

\section{El abanico aluvial del Guadalentín}

Aprovechando el portillo tectónico que se abre entre los anticlinales de la sierra de Tercia y la de La Estancias (Peñarrubia y Torrecilla en el sector), el ríorambla Guadalentín penetra en la Depresión Prelitoral murciana, circunstancia 
que hace trazar a su cauce un ángulo casi recto para seguir la orientación general hacia el NO de este amplio valle.

Suele denominarse comúnmente a este ámbito «Alto Guadalentín» pero, de hecho, esta denominación corresponde con más propiedad al amplio sector de cabecera donde confluyen diversos cauces provenientes de relieves que oscilan entre 1.200-1.500 m de altitud y a la amplia cuenca miocena (cuenca de Lorca) siempre por encima de los $600 \mathrm{~m}$. de altitud, recorrida ya por este colector principal con dirección NE-SO hasta su cerramiento por el reborde interior de la Depresión Prelitoral. A unas pendientes muy rápidas en cabecera y la presencia de materiales predominantemente impermeables (Calvo, 1968) se unen las características climáticas del Sureste español, dando lugar a la pobreza de su módulo y a un régimen singular de prolongados estiajes y crecidas de gran intensidad que arrastran gran cantidad de aluviones (Gil, 1968a).

La ruptura de pendiente que supone la entrada del Guadalentín en la Depresión Prelitoral está en el origen de un gigantesco abanico aluvial $\left(78 \mathrm{~km}^{2}\right.$ aprox.) sobre el que se asienta la vega de Lorca. Proveedor exclusivo de regadío durante siglos y dado su escaso débito y las grandes crecidas que experimenta, en su cuenca se instalaron algunos de los embalses más antiguos de España. Pero desde mucho antes la cuenca del Guadalentín se ha dotado de otras numerosas

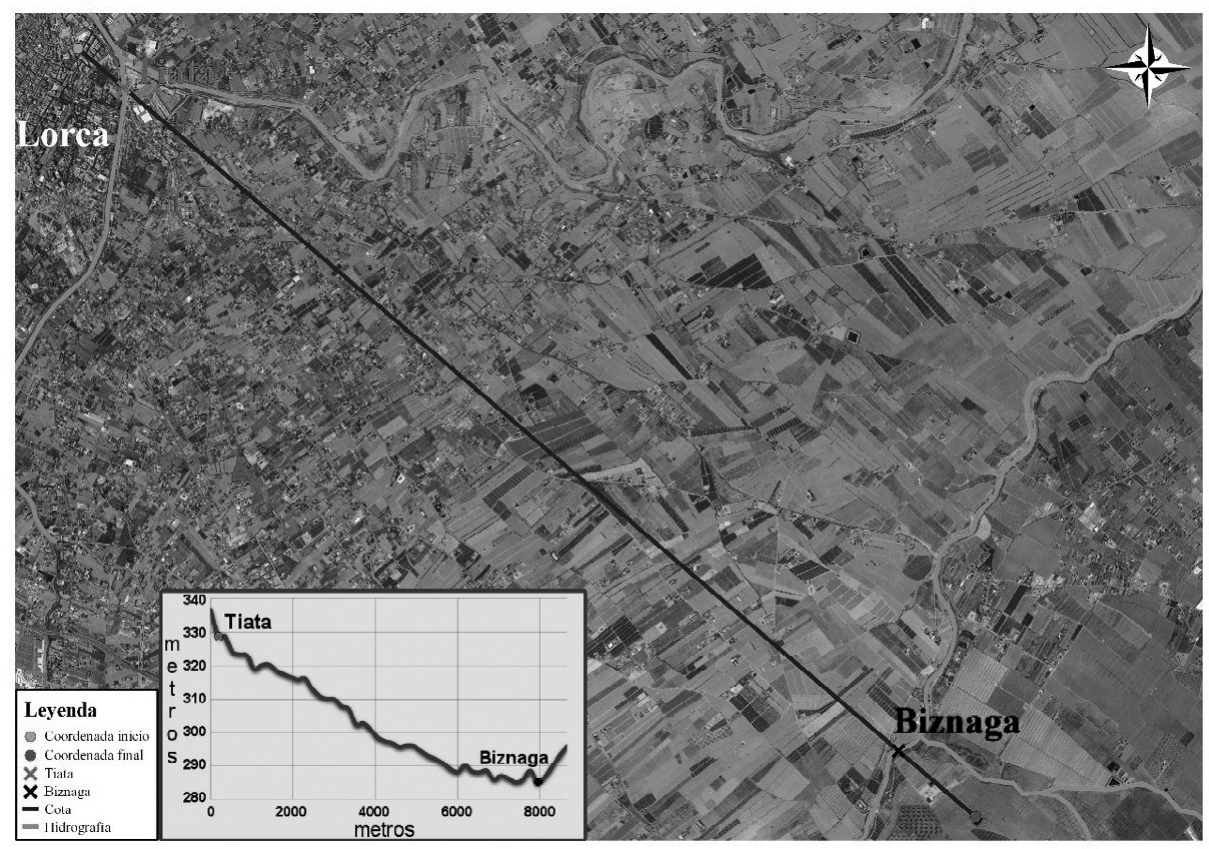

Figura.$^{\circ}$ 2. Corte longitudinal del abanico aluvial del Guadalentín frente a Lorca. 


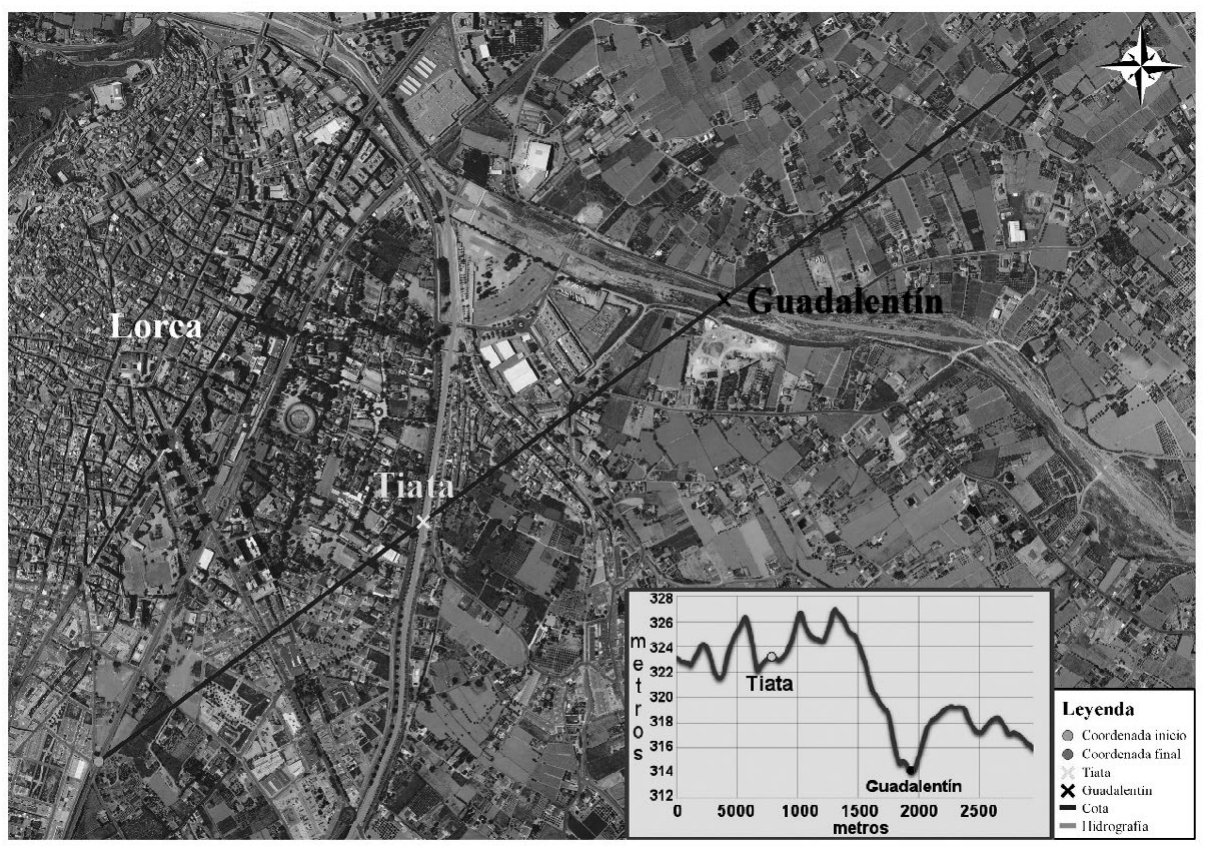

Figura.$^{\circ}$ 3. Corte transversal del cono.

obras del mayor interés, desde presas subálveas hasta derivaciones superficiales, galerías con lumbreras y otros muchos artefactos para el riego, convirtiendo a esta cuenca en un extraordinario muestrario de adaptaciones a la sequía y aprovechamiento de recursos hídricos escasos e irregulares. Se trata, en conjunto, de un patrimonio extraordinario pero al parecer escasamente valorado, dada la situación en que se encuentran muchos de sus elementos más significativos y los proyectos que actualmente se llevan a cabo, a los que se aludirá más adelante.

Las dimensiones y disposición de abanico aluvial del Guadalentín en Lorca presentan rasgos que permiten considerar la probabilidad de importantes modificaciones históricas hasta llegar a su aspecto actual. Los episodios de aportación sedimentaria han sido reconducidos artificialmente desde antiguo por una amplia red dendriforme de cauces que difunden las aguas de avenida por una extensa superficie y, de hecho, conforme nos alejamos hacia el sur del trazado del cauce del Guadalentín el perfil del cono muestra una elevación mucho mayor, que llega a alcanzar los $9 \mathrm{~m}$. (Figura n. ${ }^{\circ} 3$ ).

En cuanto a la existencia de cauces que circulan en sentido contrario a la pendiente general de la Depresión murciana sólo es posible mientras lo permita la pendiente de los flancos montañosos o del propio abanico aluvial, de manera que es bastante probable que el actual perfil de este obedezca a la prolongación 
y mantenimiento artificiales de cauces antiguos no funcionales o al establecimiento de conducciones elevadas sobre el fondo de valle que derraman lateralmente sus aguas hacia él. El llamado «canal de Bujercal», situado a cierta altura en la ladera interior del valle es un buen ejemplo de lo anteriormente señalado, así como de la dificultad del mantenimiento de la funcionalidad de conducciones con disposición normal a la circulación del agua en ladera, sus frecuentes roturas acabaron por dar lugar a su abandono.

La acumulación actual de materiales en el sector distal del cono, que se advierte en la figura $n .^{\circ}$ 2, dificulta su drenaje mediante la rambla de Viznaga hacia el Guadalentín. Sin embargo, tan solo hace trescientos años esta rambla disponía de ciertos caudales que proporcionaban charcos permanentes donde abrevaban ganados (charcos de las Paretejas, Cabezuelas, Alamico, camino de Aguaderas, Senda del Puntal, de Mateo Perez, Cambroneros, el Almendro, la Zarza...) cuidadosamente protegidos (Ordenanzas, 1713), cuyas aguas posiblemente provenían de escorrentías procedentes de los conos aluviales de la sierra de Almenara, del abanico aluvial del propio Guadalentín, y de surgencias de las aguas subterráneas de El Saladar en cabecera.

Parece, por tanto, que la dinámica natural del sector ha sido profundamente modificada desde antiguo y el resultado de estas modificaciones es que en los suelos de este abanico aluvial predominan ampliamente materiales finos, arcillosos y arcillo-limosos (el «tarquín» al que se aludirá más adelante), en tanto que los materiales más gruesos (gravas y arenas de diversos calibres) apenas aparecen en superficie.

Muy al contrario, la serie de ramblas más meridionales en ambos flancos de la depresión presentan abanicos aluviales con materiales gruesos, arenas y gravas principalmente. Sin disponer de dispositivos para riego desarrollados y sin regulación, podrían ser un buen ejemplo del comportamiento inicial del Guadalentín.

Un episodio catastrófico reciente y bien conocido ilustra esta afirmación. En la inundación de 1973, la rambla de Nogalte llegó a transportar un caudal máximo próximo a los $2000 \mathrm{~m}^{3} / \mathrm{s}$, de los cuales aproximadamente el 40 por ciento eran arrastres sólidos según se ha señalado en numerosas ocasiones. Una auténtica colada de barro y piedras que dio lugar a una catástrofe de grandes dimensiones, carga de sedimentos que es posible advertir también en el aspecto de las aguas en la figura.$^{\circ}$ 5, para la crecida de 2012. Sin embargo tampoco en el comportamiento de la crisis de 1973 podemos excluir la acción humana, debido al proceso de emigración, despoblación y abandono que se había producido en la década anterior (Capel, 1968) en amplios sectores de su cabecera, roturados y puestos en cultivo principalmente a partir de siglo XVIII. Terrazas de cultivo, boqueras, conducciones y el propio suelo de cultivo, elementos de una agricultura establecida sobre fuertes pendientes y sin mantenimiento, se 
destruyeron y fueron empujados al colector principal por un intenso aguacero que aportó en algunos sectores de cabecera más de $300 \mathrm{~mm}$ en dos horas.

\section{El Saladar}

El humedal salino conocido como «El Saladar» o «Saladar de Altobordo» ocupaba el tramo final de la depresión del Guadalentín y se presenta como el área de confluencia de diversos flujos hídricos aportados por el sistema de ramblas que lo delimitan. Esta red de avenamiento está configurada por numerosos barrancos y ramblas (básicamente Nogalte, Béjar, Torrecilla y por el Este la rambla de Purias) que muestran como característica común una gran cabecera con segmentos cortos y de fuerte pendiente que confluyen rápidamente, un tramo medio corto o muy corto y un tramo final muy amplio en forma de abanico aluvial.

Estos cauces, secos durante largos periodos, esparcen de forma divergente sus aguas ocasionales sobre sus conos y solo en ocasiones se conectan con el nivel de base a través de la rambla de Viznaga, a la que ya se ha aludido. La hisohipsa de $300 \mathrm{~m}$. delimita este ámbito que tiene su sector más bajo en el paraje denominado Los Salobrales, próximo al caserío de Altobordo (Merlos et al. 1995)

Se trata de un amplio sector que ocupa unos $35 \mathrm{Km}^{2}$, con pendientes en general inferiores al 1 por ciento, pero que en buena parte de su superficie no alcanzan el 0'5 por ciento. En la génesis de este espacio semiendorreico se conjuga la dinámica fluvial con la tectónica general de la fosa del Guadalentín, ya que se trata de una depresión de distensión que la tectónica reciente tiende a comprimir por elevación de sus márgenes montañosos (Rodríguez et al. 1993).

Reducido constantemente y desde muy antiguo por la aportación de tarquines y, posteriormente, por la disponibilidad de nuevos recursos hídricos, actualmente el sector puede calificarse de criptohumedal salino asociado a una llanura de inundación, cuya colonización agrícola tan solo ha dejado pequeños sectores aislados que muestran restos de la vegetación halófila original subsistente y afloramientos salinos (Merlos et al.1996)

Los materiales permeables que rellenan esta fosa, básicamente plio-cuaternarios y miocenos, han permitido la acumulación de aguas subterráneas que componen el denominado «Acuífero del Alto Guadalentín» que presenta distintos niveles en relación con la compartimentación tectónica de la materiales subyacentes: fosas de Escucha-Feli y de Esparragal- Villaespesa flanqueando el sector elevado de Bujercal-Los Chaparros El aprovechamiento de estas disponibilidades hídricas es muy antiguo, aunque lógicamente reducido a las más próximas a la superficie.

Algunos recursos hidráulicos no superficiales tienen también importancia en la agricultura tradicional. Tanto la presa subálvea en el Guadalentín frente a 
Lorca denominada «Fuente del Oro» como la situada en la rambla de Nogalte, dotada de un interesante sistema de galerías con lumbreras (Gomez, 2004), así como algunas otras (Gil Meseguer, 2007), proporcionado tradicionalmente caudales más bien modestos destinados al riego. Pozos y aljibes completaban el aprovechamiento de caudales subterráneos, reducidos a las disponibilidades más superficiales. Tan solo a partir de los años 30 del siglo XX se inicia la explotación de recursos más profundos, aunque el desarrollo de las extracciones masivas se retrasará hasta los años sesenta en relación con la aplicación de sistemas de extracción más avanzados.

\section{LA CRECIDA, RECURSO Y PELIGRO}

Con estas condiciones naturales, parece bastante evidente que el área reúne todas las características necesarias para calificarla como un espacio de catástrofe. El riesgo de inundación es muy elevado y frecuente incluso en la actualidad, cuando se han instalado infraestructuras de defensa que son claramente insuficientes y la ocupación humana se ha hecho muy intensa. La inundación catastrófica de 2012, a la que se aludirá más adelante, así lo ha puesto en evidencia.

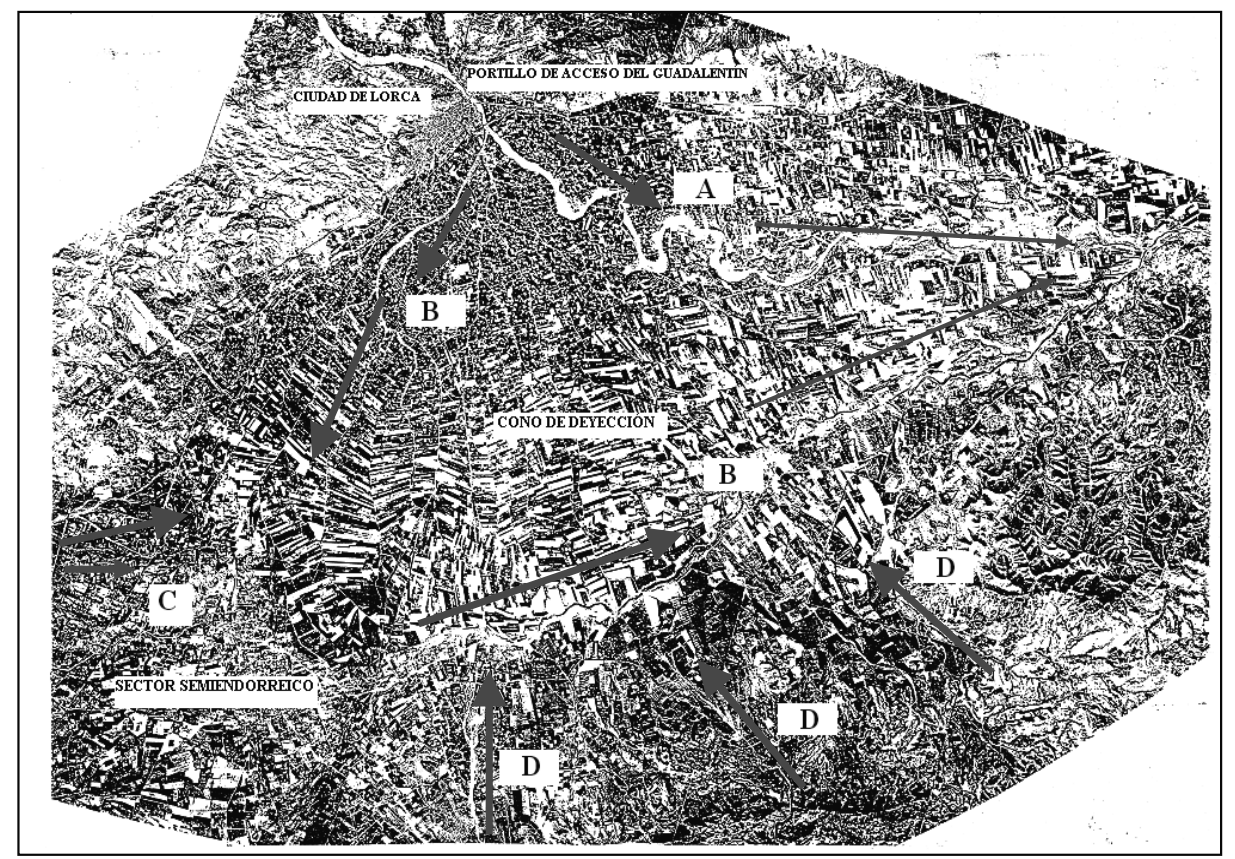

Figura n. ${ }^{\circ}$ 4. La circulación general de las aguas en el sector meridional de la Depresión Murciana: A) Cauce del río Guadalentín. B) Ramblas de Tiata y Biznaga. C) Aportaciones de las ramblas de Nogalte y otras. D) Ramblas de flanco meridional de la depresión. 
El sentido general de la circulación de las aguas que expresa la figura . $^{\circ} 4$ muestra claramente un amplio espacio inundable en el sector denominado El Saladar. Un espacio durante siglos semiabandonado o con el aprovechamiento propio de estos sectores y que progresivamente se ha bonificado atrayendo poblamiento. Otras áreas sensibles son aquellas donde los núcleos urbanos se ubican inmediatos a un cauce, con una vulnerabilidad física que se acrecienta con el tamaño de su caserío y actividad económica.

Esta circunstancia, más o menos percibida por las administraciones afectadas, pero con harta frecuencia tan solo después de concretada la calamidad, ha impulsado desde principios del siglo xx hasta 1985 a la elaboración de más de 130 proyectos de protección, realizados en su mayor parte y concretados en la corrección hidrológica de los barrancos de cabecera de las ramblas que desembocan por el sector meridional de la depresión del Guadalentín, procedentes del conjunto sierra de Las Estancias-Torrecilla (términos municipales de Vélez Rubio, Vélez Blanco y Chirivel), así como de diversos cauces que vierten al embalse de Puentes, acompañadas estas últimas de mejoras en dicho embalse y en el de Valdeinfierno (Conesa, 1985).

También se acometen en ese periodo trabajos en el área urbana de Lorca y en los cauces del cono de deyección del Guadalentín. De estos últimos cabe señalar las mejoras en el partidor de Los Sangradores, en la rambla de Tiata y en diversos cauces de regadío. Así mismo se realizan obras en las ramblas de Béjar y Nogalte, consistentes básicamente en el establecimiento de pequeños diques de contención.

El ambicioso Plan de Defensa contra Inundaciones de 1987, actualmente ejecutado prácticamente en su totalidad, en este sector se reduce a la construcción de un nuevo embalse en Puentes y el recrecimiento del de Valdeinfierno, olvidando el resto de cauces del área y, muy en particular, el conjunto de ramblas procedentes de las estribaciones de la sierra de Las Estancias.

\section{La protección inmediata de los núcleos urbanos}

Los intentos de proteger los núcleos de población frente al riesgo de inundación tiene una cierta tradición en Lorca y mucho más breve en Puerto Lumbreras, los dos núcleos urbanos más importantes del área aunque muy desiguales en sus dimensiones.

El encauzamiento del río Guadalentín a su paso por Lorca es una necesidad sobrevenida en épocas relativamente recientes, hasta que se desarrolla el caserío en el barrio de San Cristóbal (paralelo a la margen izquierda del río) y posteriormente se produce una importante ocupación industrial ya en los inicios del siglo Xx. 
El emplazamiento elevado del núcleo de Lorca aleja la posibilidad de afección por inundaciones en su mayor parte, tanto más cuanto su crecimiento se efectúa alejándose del río, hacia el que presenta un frente urbano muy reducido y protegido por una muralla. Los problemas derivados de la presencia del Guadalentín y, en particular de sus ocasionales crecidas son, en estos años, básicamente de incomunicación entre ambos sectores del núcleo de Lorca y, por supuesto la posibilidad de graves inundaciones catastróficas.

El sector más afectado por ambas situaciones es el arrabal de San Cristóbal, situado en la margen izquierda del cauce a partir de siglo XVIII (Gil, 1968b), y que se desarrolla paralelo al cauce y a poca altura, con lo que sufre de lleno las crecidas del Guadalentín, quedando también aislado del resto de la ciudad, emplazada sobre la margen derecha.

Otro barrio, desarrollado también en el mismo siglo, en relación con la celebración de ferias, es el de Santa Quiteria que se ve afectado por las aguas altas del Guadalentín derivadas por la rambla de Tiata y hubo de protegerse desde el último tercio del siglo, poniendo en la margen izquierda de este cauce un tramo de muro de mampostería.

El paso entre el barrio de San Cristóbal y la ciudad es, con mucho, el más importante, ya que no sólo dificulta el funcionamiento urbano sino que también corta importantes vías de comunicación, tanto hacia Andalucía como hacia el interior de la Región de Murcia. En este sector el amplio cauce mayor del Guadalentín, muy poco encajado, plano, ancho y con el cauce menor anastomosado propio de una rambla, permitía la comunicación entre ambas márgenes directamente a pie o mediante cortas pasarelas de tablas, forma de comunicación que se señala en 1850 (Madoz, 1850) como la única para cruzar las muy escasas aguas permanentes del río. Por ello las primeras iniciativas parece que se encaminaron más a fijar un pequeño canal permanente de aguas perennes que a otra cosa. La travesía del Guadalentín se soluciona definitivamente en 1879, cuando se inaugura el Puente del Barrio de San Cristóbal, obra de bella traza y gran solidez, pese a su existencia las pasarelas de madera sobre el Guadalentín han perdurado hasta más allá de la primera mitad del siglo XX.

En cuanto al problema de las inundaciones será ya en 1806 cuando se proyecta un muro de mampostería de cinco metros de altura entre la ermita de Madre de Dios de la Peña y la llamada Cuesta de Ferrer, que habría de dar protección a la populosa barriada de San Cristobal. Pero la primera canalización del cauce del Guadalentín habrá de esperar hasta 1923 con características similares, al parecer, a las de las defensas instaladas más de un siglo antes. Su inutilidad habría de demostrarse trágicamente en la inundación del 19 de octubre de 1973, que causó en la ciudad trece muertos y daños cuantiosos en viviendas y actividades económicas. 
La nueva canalización, declarada de urgencia tras la catástrofe, no se finalizará hasta dos años más tarde, con una longitud de $1.200 \mathrm{~m}$. entre La Peñica y el puente del ferrocarril (antiguo «Puente de Hierro»), dragando también el cauce hasta dejarlo entre 3 y 5 metros más bajo. Construida con muros de hormigón de forma trapezoidal adopta, sin embargo, una curiosa forma de embudo ya que en su origen el cauce tiene una anchura de 100 metros en tanto que a la altura de los dos puentes del ferrocarril actuales apenas alcanza los 46. Quizá para compensar este evidente error en 1981, tras acabar las obras del cauce principal, se procede al dragado y canalización de la rambla de Tiata a lo largo de 3.000 metros a partir de Los Sangradores, aumentando así la capacidad de evacuación de la rambla hasta los $150 \mathrm{~m}^{3}$ por segundo, reforzando también la conexión entre el partidor y el canal en años posteriores.

Pese a todo la canalización del cauce del Guadalentín resulta insuficiente ya que no evita que las aguas de avenida, en su margen izquierda, inunden las
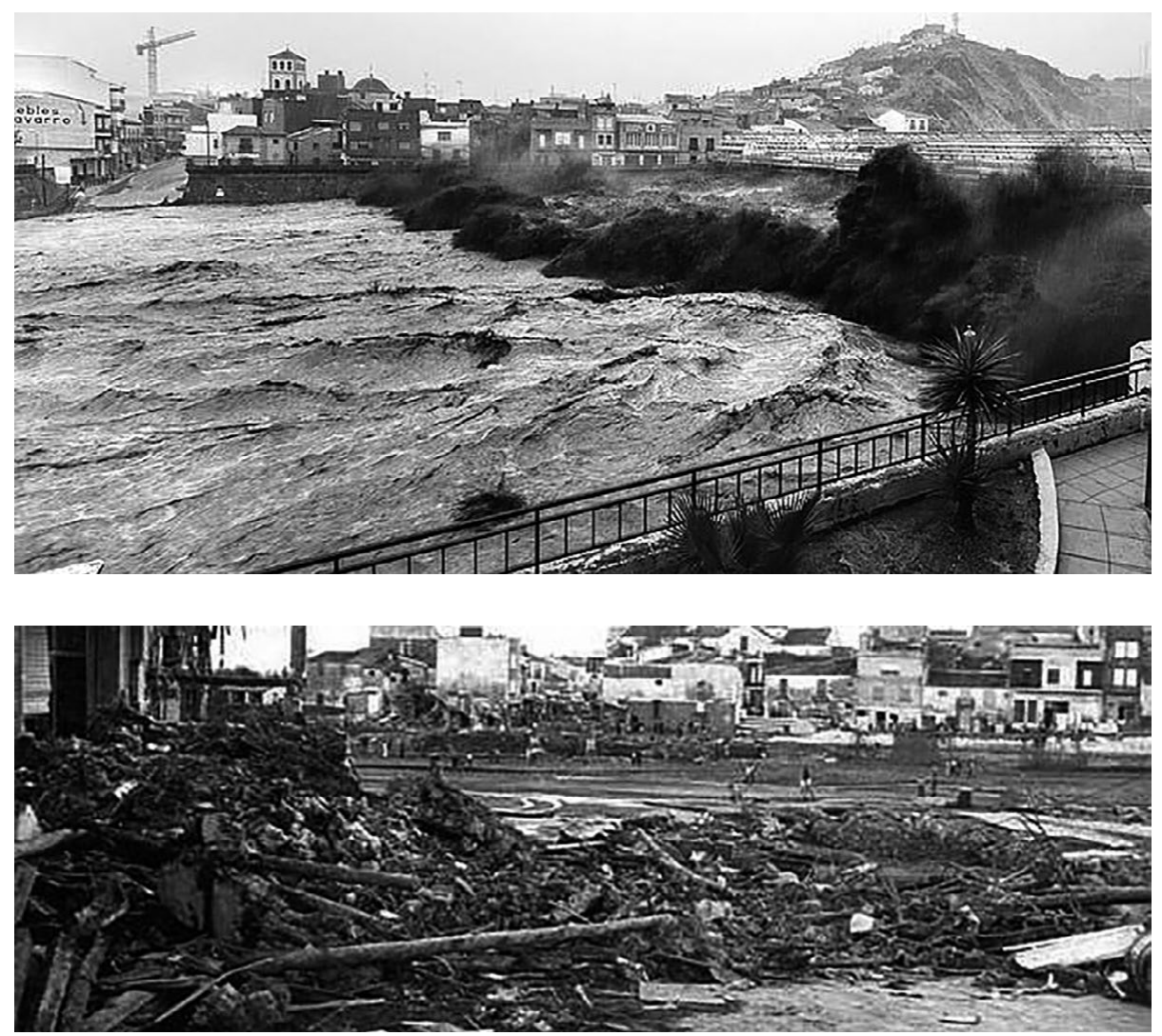

Figura n. ${ }^{\circ}$ 5. Arriba: La canalización de la rambla de Nogalte al paso de la crecida de 2012 por el núcleo de Puerto Lumbreras. Abajo: El mismo sector tras la inundación de 1973. 
explotaciones agrícolas y viviendas de la Ribera de San Miguel y a las numerosas fábricas existentes en el polígono industrial de Serrata, sector que se ve afectado también por las aportaciones de la Rambla Salada.

Se han realizado también algunas actuaciones en varias ramblas pequeñas que atraviesan sectores urbanos, cubriendo un tramo del canal de La Pulgara y embovedando parcialmente las ramblas de Las Chatas y de Las Señoritas en el barrio de La Viña. El propio callejero lorquino que se emplaza sobre la ladera de la sierra del Caño, muestra varias adaptaciones interesantes a las crecidas de los ramblizos que la surcan (Calvo, 2003).

En el caso de Puerto Lumbreras, emplazado en ladera y alejado de la rambla de Nogalte hasta el siglo pasado, prácticamente no existen antecedentes de interés hasta que la catástrofe de 1973 impulsó la canalización de un amplio tramo urbano, finalizado en 1978, al que se añadieron posteriormente diques trasversales de hormigón sobresaliendo unos $15 \mathrm{~cm}$ sobre el lecho fluvial que, al parecer, buscan restar velocidad a las aguas y evitar el arrastre de tierras. También se establecieron diques y muretes de contención aguas arriba en la rambla. Actuaciones insuficientes que se han vuelto a repetir tras la inundación de 2012 en cabecera, ya en el límite con el municipio de Vélez Rubio. Sin embargo, en este caso, la canalización del tramo urbano de la rambla de Nogalte fue suficiente para evitar daños en el caserío.

\section{Beneficios de la crecida: los tarquines}

Las aportaciones sólidas transportadas por las aguas del Guadalentín en crecida han jugado un papel de primer orden en la agricultura de este sector: "en la parte llana de dichas tierras abiertas se halla una substancia o flor de tierra que arrastran las aguas de las alturas y cabezos, la qual se compone de un limo mezclado con arenilla sumamente menuda, a cuyo compuesto dan los naturales el nombre de «tarquín»...Esta tierra...es muy suelta y dócil al arado, siendo extraordinariamente fecunda» (Correo...1795).

Estas aguas, denominadas «turbias» por contraposición a las provenientes directamente de los embalses de cabecera o de alguna otra fuente de menor importancia, que reciben el nombre de «claras», tienen una doble función de gran importancia que justifica el hecho de que se regule su uso incluso cuando el sistema de riegos de la huerta de Lorca a partir del embalse de Puentes está ya en funcionamiento, como se advierte en la Ordenanza Provisional para la venta de las aguas destinadas al riego de Lorca de 1891 (Ordenanza, 1936).

La doble utilidad de los riegos de turbias, antes aludida, deriva del hecho de que «estos tarquines o limos, en la manera que se hallan cuando los arrastran las crecidas, que siguen inmediatamente a las grandes lluvias, son abono utilísimo en la agricultura, especialmente para los salobrales» (Vallejo, 1833). 
Abono y humedad para tierras en cultivo y, además, posibilidad de extenderlo por las inmediatas tierras del humedal continental asociado a una llanura de inundación que se denomina en Lorca «El Saladar», lavando las sales y depositando sobre ellas depósitos de suelo fértil.

Las crecidas que tradicionalmente aportaban tarquines provenían del propio Guadalentín y las ramblas de Béjar, Torrecilla, Alta y Nogalte. Estas aportaciones han disminuido sensiblemente a lo largo del tiempo debido a los embalses construidos en el Guadalentín, aunque todavía llegan las procedente de la amplia cuenca de Lorca (aguas abajo de los reservorios) y del resto de ramblas citadas. Pero todavía en 2012 el Guadalentín aportó a su paso por Lorca un máximo instantáneo superior a $600 \mathrm{~m}^{3} / \mathrm{s}$ tras quedar los embalses de cabecera al límite de su capacidad, en tanto que, en la misma fecha la rambla de Nogalte llegó a transportar más de $2000 \mathrm{~m}^{3} / \mathrm{s}$. en el momento de máxima intensidad de crecida.

Esta aportación de aguas ocasionales está reglamentado en su distribución a través de los cauces de este campo regado y aparece como un complemento del que se realiza con aguas perennes: «el día que venga aguaducho, el que no fuere regador de aquel día no puede tomar mas agua que la que saltare por encima del acequia, y que en ninguna parte hagan rafa, e que si el aguaducho no saliere fuera de la cequia que sea del regador de aquel día, e que otro alguno no la tome» (Ordenanzas, 1713).

Se trata de un riego rigurosamente conducido por la red de acequias, tanto de riego permanente como aquellas otras dispuestas para este tipo de aportaciones ocasionales, con lo que es la propia intensidad de la crecida la que determina la superficie que recibe caudales, pues «no se puede llevar agua de un brazal a otro excepto cuando viene crecida de manera que no se puede partir». Por supuesto que en los episodios de inundación el agua circularía libremente saturando el sistema de conducciones.

Posiblemente la descripción más detallada de estas aguas de crecida, de la composición de sus arrastres y su utilidad para la agricultura del área, sea la de José Musso Valiente que viene incluida en el tomo tercero del Tratado sobre el movimiento y aplicaciones de las aguas de José Mariano Vallejo (ver bibliografía). Este escrito, publicado en 1833, corresponde a un momento en que el Guadalentín no está regulado ya que, de los dos embalses dieciochescos de Valdeinfierno y Puentes, el primero estaba inutilizado por colmatación de su vaso y el segundo inoperante tras su rotura en 1802. En aquellos años el área que potencialmente podría beneficiarse más directamente por las aguas de crecida, ya que se trataba de suelos salinizados, ascendía a 30.800 fanegas de 4000 varas cuadradas, superficie sobre la que, según este autor, podía depositarse «una capa de más de cuatro dedos, y algunas veces de un palmo de grueso» de tarquín.

No obstante las ventajas de esta aportación de suelo, el regadío tradicional de Lorca seguía necesitando de aportaciones de riego para mantener la fertilidad 
y se enfrentaba con el problema del endurecimiento de estos sedimentos, obligando a un mantenimiento permanente del sistema de distribución para evitar su rápida inutilización.

\section{ELEMENTOS ESENCIALES DEL APROVECHAMIENTO DE AGUAS TURBIAS}

El sistema de conducción de aguas permanentes para riego han sido ampliamente estudiado (Gil Olcina, 1971) y su transformación en cauces de distribución de aguas turbias no depende más que del volumen de aportaciones del Guadalentín. Las aguas de crecida pasan de unas acequias a otras rompiendo la compleja organización de la administración del regadío hasta que una crecida excepcional circularía en lámina sin respetar cauces ni partidores y extendiendo diversos tipos de sedimentos por distintas áreas.

Los efectos de estas circunstancias sobre el territorio agrícola se advierten desde muy antiguo, clasificando las tierras según su disponibilidad de agua permanente, situación y condiciones edáficas. Ya en los siglos XIII y XIV, al repartir las tierras de Lorca entre los repobladores castellanos (Torres, 1977) los lotes distribuidos tiene distinta superficie según se trate de tierras de huerta, de morgón, de fondón o de saladares.

A pesar de que el aprovechamiento de aguas turbias no solo es aleatorio en el tiempo, sino que exige la presencia de los agricultores en sus campos durante la crecida para tratar de encaminar las aguas de forma idónea y estas, por su exceso, pueden desembocar en calamidades; este conjunto de circunstancias no han impedido sino más bien impulsado que, a lo largo del tiempo, se instalen sobre el Guadalentín diversas infraestructuras destinadas a encaminar adecuadamente y extender sobre el máximo espacio posible los flujos de turbias. A las más importantes de ellas nos referimos continuación

\section{Los Sangradores}

La distribución de las aguas permanentes del Guadalentín se ha realizado desde un primer momento mediante el sistema de partidores (boqueras) situadas en ambas márgenes del río. Aunque en muchos casos las tomas de agua se hacen directamente de la margen del río cuando la topografía lo permite, con frecuencia la derivación se hace mediante una presa, generalmente construida con madera, cañas y tierra, que suele denominarse «atochada» y que también se utiliza para derivaciones en cauces menores. Se trata, sin duda, de un dispositivo muy frágil pero también de fácil reconstrucción.

En principio estas tomas y partidores se ubicaban inmediatos y aguas arriba de la ciudad de Lorca, con finalidad de regar sectores que actualmente están mayoritariamente ocupados por el desarrollo urbano, estableciéndose incluso 
depósitos con este fin como el de La Alberca, inmediato a la Puerta de San Ginés del recinto amurallado.

La derivación de Los Sangradores es la más importante de estas derivaciones, hasta el punto que en la red tradicional de riego a partir de ella parten más conducciones del cauce derivado que del propio río Guadalentín. Se trata, de hecho, de una boquera de enormes dimensiones, que con los dos brazos en que divide el río: rambla de Tiata y El Ramblar, componen un dispositivo hidráulico amplísimo, determinante de la estructura general del regadío tradicional lorquino e íntimamente relacionado con la morfología del abanico aluvial del Guadalentín. Encaminado a la mejor administración posible tanto de las aportaciones ordinarias del río como a sus frecuentes crecidas extraordinarias es, sin duda, un buen ejemplo de adaptación al medio, ya que es capaz de paliar los efectos de una inundación diseminando la onda de crecida y, al mismo tiempo, regar y fertilizar con sus aluviones («riego de turbias») un amplio territorio y colaborar en la desalación de los sectores semiendorreicos que flanquean el abanico del Guadalentín en su sector meridional.

Con origen indeterminado y situado siempre muy cerca del núcleo urbano de Lorca aunque con emplazamientos diferentes, se tiene ya constancia de la existencia de una presa en el siglo XVII (presa de La Torta).En 1733 se construyen los primeros Sangradores de obra con sus compuertas laminadoras, los cuales quedarán destruidos por diferentes riadas.

Las «Ordenanzas» de 1831 (Ordenanzas, 1831) establecen ya claramente la distribución de las aguas de avenida e incluso la posibilidad de destruir las derivaciones existentes, incluyendo la que envía las aguas por la rambla de Tiata, para que el agua siga el cauce del Guadalentín en caso de una crecida extraordinaria: «cuando la avenida de aguas turbias fuese en tanta cantidad que corran riesgo los frutos de campo y huerta, y aun las habitaciones de sus moradores, podrán [...] y aun romperse la atochada contigua, entendida por el Sangrador grande y el malecón de la Cuesta de Ferrer, si se considerase necesario» (capítulo XIV, artículo 9).

Esta regulación, establecida en principio dentro de la del uso de aguas turbias y sus sangradores tiene, sin embargo, unas importantes consecuencias al permitir que los caudales de crecida del Guadalentín se dirijan directamente hacia la ciudad de Murcia y su huerta, dando lugar en determinadas circunstancias a situaciones de gran catástrofe, como se ha descrito para la inundación de 15 de octubre de 1879 (Calvo et al. 2001)

La apertura o mantenimiento de estas derivaciones ha generado, lógicamente, graves diferencias entre las autoridades de ambas ciudades, que se pusieron de manifiesto en las inundaciones de 1946 y 1948. Cerrados los partidores de Lorca el agua inunda su huerta y campo, expandiendo la crecida y retrasando su desembocadura en el Segura al ser recogidas por la rambla de Biznaga antes 


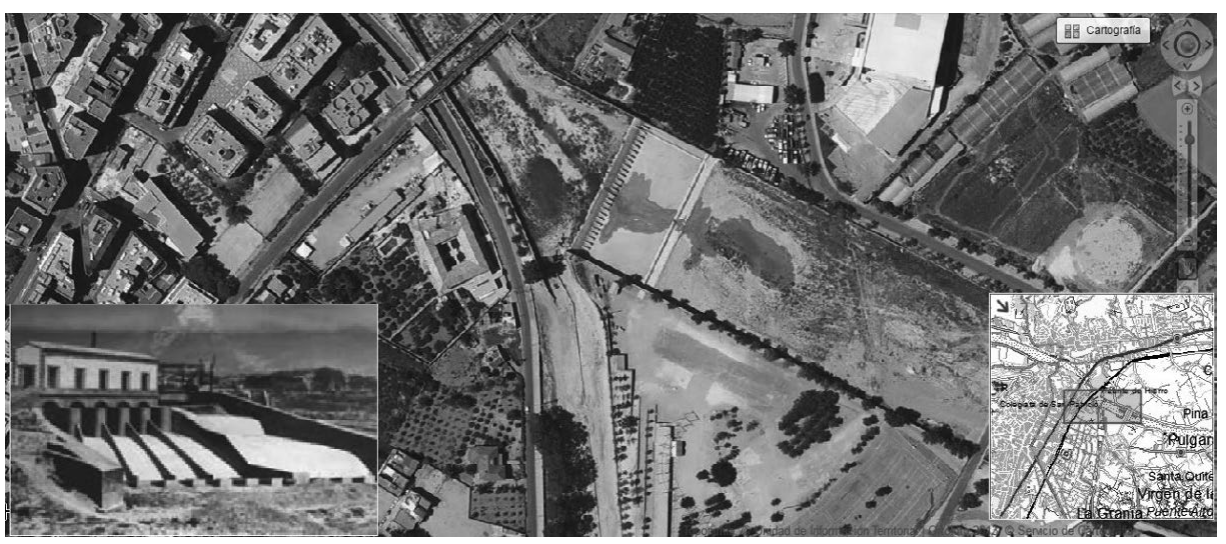

Fig. 6. Derivación de Los Sangradores de Lorca.

de llegar de nuevo al Guadalentín. En caso contrario las aguas se dirigen directamente hacia Murcia incrementando la crecida del Segura.

El reciente aumento de la capacidad del canal de derivación al mar desde la presa de El Paretón frente al núcleo de Totana y la construcción del embalse de El Romeral, ambos en el tramo bajo del Guadalentín, ha alejado el peligro de la ciudad de Murcia, pero no ha solucionado la situación en Lorca, como se señalará más adelante.

A lo largo del siglo xx Los Sangradores se acondiciona en varias ocasiones (1929 y 1952) modernizándolos con compuertas semiautomáticas. La riada de 1973 provocó graves desperfectos y no será hasta 1984-86 cuando se construyan de nuevo cambiando su emplazamiento al actual.

Una derivación similar con compuertas automáticas se sitúa en el canal de la Condomina, que sirve para controlar el paso de las aguas de avenida del Guadalentín a las tierras de Marchena a través de los canales de la Condomina y de Contreras. La primera presa de mampostería la construyó la Confederación Hidrográfica del Segura en 1930, sustituyendo a un malecón de tierra.

\section{La rambla de Tiata}

Una vez que el Guadalentín atraviesa el portillo entre los relieves de la sierra del Caño y las estribaciones de la de Tercia, sus aguas alcanzan la depresión prelitoral, pasando bruscamente a la casi horizontalidad de la fosa tectónica. En este sector, como se ha señalado, se ubican las presas de derivación del regadío inmediato al núcleo lorquino y aquellas destinadas a conducir caudales hacia el fondo de la depresión.

Los escritores musulmanes ya describen esta utilización del agua para riego mediante derivaciones, así lo indica al-Udri en el siglo XI y, tres siglos después, 
al-Himyari, precisa que el río tiene dos cauces diferentes a distintas alturas, de manera que el agua tiene que elevarse para utilizarla en regadío a través de uno de estos cauces (Arcas, 1985). Las descripciones de autores musulmanes han sido interpretadas por varios autores (Molina, 2006) y aunque las tomas de agua por derivación son muy numerosas a lo largo de este tramo alto del Guadalentín, por su transcendencia para el regadío y sus dimensiones hacen muy posible que esta referencia haga alusión al papel de la rambla de Tiata que permite la aportación de caudales a la mayor parte del cono aluvial de este río en Lorca. Se trataría de una posible trayectoria del cauce original al divagar dentro de su cono hasta cegarse con sus propias aportaciones y que ha sido mantenido después abierto, de forma artificial, por su utilidad para el riego de un amplio sector de la huerta y campo lorquinos (parajes de Torrecilla, Campillo, Purias, Bujercal, Esparragal y La Escucha) y para la desalación de los sectores semiendorreicos. Los estudios de toponimia parecen abundar también en este sentido, señalando la importancia de la rambla de Tiata en un regadío posiblemente anterior a la presencia árabe (Pocklington, 1986).

La descripción del sistema de riegos antiguo más completa y utilizada no contradice esta posibilidad, ya que señala que los caudales correspondientes a la Alquería de Albacete, incrementados por los de la presa subálvea de la Fuente del Oro, se subdividen en varios brazales de los cuales «otro hacia el S. por la orilla de la rambla de Tiata, que ahora lleva aquel nombre» (Musso Fontes, 1847). Un cauce, por tanto, al que se le devuelve la funcionalidad aportando caudales derivados artificialmente. Tanto la cartografía como las «vistas» de los siglos XVIII y XIX (Espinalt, 1778; Martínez de Lara, 1781; Ayuntamiento de Lorca, 1846) muestran con claridad como la rambla de Tiata es un elemento esencial en el sistema hidráulico del abanico del Guadalentín, hasta el punto que el cauce de este último no se representa.

Las aportaciones de esta rambla pasan rápidamente a lo largo de su trayecto de arenas gruesas y finas a arcillas y arcillas limosas, componentes básicos del denominado tarquín, al que se ha aludido con anterioridad. En el sector oriental del abanico aluvial, por donde circula el Guadalentín, las texturas predominantes son arcillosas con muy escasa presencia de materiales más gruesos y el río, sin canalizar, tiende a desarrollar amplios meandros.

Acondicionada en diversas ocasiones, asegurando sus márgenes que progresivamente ocupa el desarrollo urbano de la ciudad de Lorca, está también cruzada por varios puentes entre los que destaca el llamado «Puente de la Torta», obra de 1910 en hormigón armado y un solo vano, posiblemente una de las primeras de este tipo construidas en España.

Desde 1981, la rambla de Tiata está dragada y canalizada, consiguiendo así que posea una capacidad de evacuación ya indicada con anterioridad. Sin embargo, en el momento presente, se está procediendo a rellenar este cauce para 


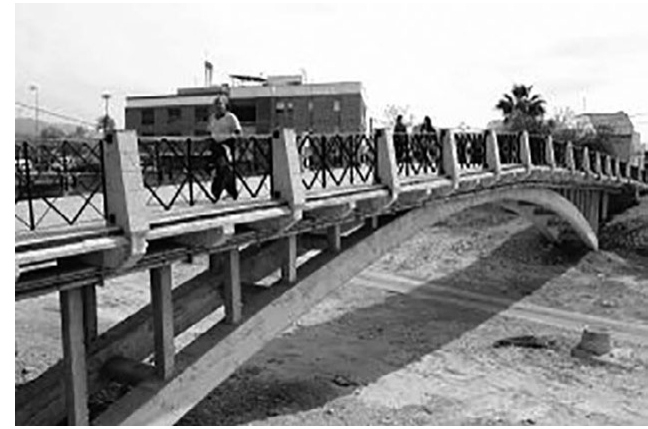

Fig. 7. Puente de la Torta sobre la Rambla de Tiata

instalar sobre él una vía de circulación automovilística, de manera que las aguas circulantes lo harán entubadas, habiendo establecido la Comunidad de Regantes de Lorca que basta para sus necesidades una tubería de hormigón armado de casi un kilómetro de longitud y con una capacidad de $8 \mathrm{~m}^{3} / \mathrm{s}$. Enterrándose también otros servicios mediante tuberías (Ayuntamiento de Lorca/ TRAGSATEC, 2015).

Este amplio proyecto en ejecución supone la construcción de un nuevo puente sobre el Guadalentín donde actualmente solo hay un vado, un vial que afectará de lleno el dispositivo de Los Sangradores y la desaparición de la rambla de Tiata.

\section{CONCLUSIONES}

Los intentos de construcción de embalses en la cabecera del río Guadalentín, de complicada historia que se inicia en el siglo XVII (Bautista; Muñoz, 1986), se concreta definitivamente en 1884, cuando el denominado «Puentes 3» comienza su explotación y con ello el régimen de este río se altera definitivamente. Es el inicio de un largo proceso que busca aumentar los caudales disponibles para riego pero, al mismo tiempo, evita en parte la circulación de caudales de avenida cargados de sedimentos, iniciándose así no sin polémica el declive del sistema tradicional de riegos de turbias en Lorca.

Otras aportaciones posteriores, provenientes sucesivamente de la explotación masiva de los acuíferos del «Alto Guadalentín» a partir de 1960, del Trasvase desde el Tajo desde 1979 y la construcción de un nuevo embalse de Puentes (IV) en 2000 han permitido una transformación muy profunda en todos los aspectos del ámbito agrario, que ha sido interpretada y descrita, para Lorca y para el conjunto de la Región de Murcia, por el Profesor A. Morales (Morales, 2001).

Sin embargo el sistema de riego con aguas turbias ha pervivido en Lorca prácticamente hasta el presente, básicamente porque la reducida capacidad del anterior embalse de Puentes y la inexistencia de regulación en el resto de cauces del área permitían la repetición de las crecidas.

La situación actual resulta un tanto paradójica. Como se manifestó claramente en la inundación del 28 de septiembre de 2012, las aportaciones del Guadalentín se vieron reducidas sensiblemente por la nueva presa de Puentes y 
la de Valdeinfierno, pero esta circunstancia no evitó que el conjunto de ramblas de flanco interior de la depresión inundaran catastróficamente el antiguo sector de El Saladar, incluyendo víctimas humanas e importantes daños en infraestructuras, viviendas y otras instalaciones de servicios, que una desacertada política territorial había ubicado en los sectores más bajos de este sector.

La laminación de las presas de cabecera permitió que el caudal máximo del Guadalentín se redujera a $616 \mathrm{~m}^{3} / \mathrm{s}$ a su paso por Lorca, caudal que pudo absorber la canalización existente sin provocar daños. Pero las aportaciones de las demás ramblas inundaron el sector meridional de la depresión hasta que, drenadas con dificultad por la rambla de Viznaga, al unirse al Guadalentín elevaron de nuevo su caudal a $1082 \mathrm{~m}^{3} / \mathrm{s}$ aguas abajo de Lorca, provocando daños materiales. La derivación del azud del Paretón frente al núcleo de Totana desvió finalmente la mayor parte de estos caudales al Mediterráneo. Un tardío deslinde de la rambla de Viznaga, que se realiza en el presente, pretende evitar la extendida práctica de invadir con cultivos y edificaciones estos cauces de aguas ocasionales, después de muchos años en los que prácticamente se había borrado o estrechado su álveo, cultivándolo e incluso ocupándolo con viviendas e instalaciones agrícolas.

Hoy es posible valorar que, efectivamente, la protección actual de la ciudad de Murcia y su huerta tiene un nivel elevado, pero también es posible señalar que no es este el caso de la comarca lorquina. La corrección de algunos meandros y la instalación de más diques de contención no soluciona en absoluto el problema en cauces como la rambla de Nogalte, sobre todo cuando no se advierte interés especial en adoptar otros puntos de vista, de carácter urbanístico o de usos del territorio, en las políticas de defensa aplicadas (Pérez Morales, 2011).

Al mismo tiempo, y como se ha indicado, la antigua conducción de la rambla de Tiata está en camino de desaparecer sustituida por un vial destinado a facilitar el tráfico automovilístico. Con ello desaparece, cuando menos, un elemento esencial del patrimonio tradicional del regadío lorquino. No parece excesivo concluir que las autoridades competentes están llamadas a revisar ampliamente tanto las políticas urbanísticas como la eficacia real de la prevención de inundaciones en el área.

\section{BIBLIOGRAFIA}

ARCAS CAMPoy, M. (1985): «Lorca en los textos árabes», en III Ciclo de temas lorquinos, Caja de Ahorros de Alicante y Murcia, Lorca, pp. 49-65

Ayuntamiento de Lorca (1846) Plano Geométrico de la Población, Archivo Municipal de Lorca.

Ayuntamiento de Lorca/Tragsatec.(2015): Proyecto de construcción de la vía de evacuación acceso Lorca-Sur-Central. Memoria. Ayuntamiento/Tragsatec, Lorca. Memoria y planos 
Bautista Martin, J.; Muñoz Bravo, J. (1986): Las presas del estrecho de Puentes, Confederación Hidrográfica del Segura, Murcia, 256 pp.

Calvo García-Tornel, F. (1968): «La huerta de Murcia y las inundaciones del Guadalentín», en Papeles del Departamento de Geografía, no 1, pp.111-132

Calvo García-Tornel, F. (2003): «Rellanos, «anchurones» y rincones. Espacios que no llegan a plazas», en Plazas de Lorca, Ayuntamiento de Lorca, Lorca, pp. 11-17

Calvo García-Tornel, F.; Conesa Garcia, C.; Álvarez Rogel, Y. (2001): «La inundación de octubre de 1879 en el Bajo Segura. Magnitud y efectos inducidos» Estudios Geográficos, n 242, pp. 7-27.

Capel Saez, H. Lorca capital subregional, (1968): Cámara Oficial de Comercio e Industria, Lorca, $260 \mathrm{pp}$.

CONeSA GARCíA, C. (1985): «Inundaciones en Lorca (Murcia): riesgo y expectación», en Papeles de Geografía (Física), n 10, pp. 33-47.

Conesa Garcia, C.; Solis, L.; Sanchez Medrano, R.; Cabezas, F. (1994): «Aplicación de técnicas de prospección geoeléctrica al estudio de la evolución de formas de drenaje y facies sedimentarias del Cuaternario en el Valle del Guadalentín», en Cuadernos de Geografia, no 55, pp. 1-15.

Correo Mercantil de España y sus Indias, (Lorca): $\mathrm{n}^{\circ}$ 80, 81, 82, 83 y 84. Madrid. Números correspondientes a octubre de 1795.

Espinalt y Garcia, B. (1778): Atlante español. Tomo 1, Reyno de Murcia, Imprenta de Pantaleon Aznar, Madrid, 217 pp.

Gil Meseguer, E. (Coord) (2007): Sistemas locales de recursos propios de agua en la Región de Murcia: minados y galerías, Murcia, Universidad de Murcia, 189 pp.

Gil Olcina, A. (1968 a): «El régimen del río Guadalentín», en Saitabi, nº 18, pp. 163-181.

Gil Olcina, A. (1968 b): «La Ciudad de Lorca (Notas de Geografía Urbana)» Papeles del Departamento de Geografía, $\mathrm{n}^{\circ}$ 1, pp. 79-110

Gil OlcinA, A. (1971): El campo de Lorca. Estudio de Geografía agraria. Valencia: Departamento de Geografía/C.S.I.C., 1971. 207 p. y láminas. Existe una segunda edición revisada de 2004 editada por el Ayuntamiento de Lorca.

Gomez Espin, J. M. (2004): Aprovechamiento integral del agua en la Rambla de Nogalte (Puerto Lumbreras-Murcia), Murcia: Universidad de Murcia, 190 pp.

Martinez de LaRA, J. (1781) Plano y vista de la ciudad de Lorca formado por orden de su Ayuntamiento. Archivo Histórico Nacional

Madoz, P. (1846-1850) Diccionario Geográfico-Histórico-Estadístico de España y sus posesiones de Ultramar, Madrid, $16 \mathrm{t}$.

Merlos Martínez, A.; Navarro Hervás, F.; Rodriguez Estrella, T. (1995): «Rasgos físicos y factores reguladores del Saladar de Altobordo (Lorca, Murcia)» Papeles de Geografia, no 22, pp. 143-167

Merlos Martínez, A.; Navarro Hervás, F.; Calvo García-Tornel, F. (1996): «El saladar de Altobordo: sectores, situación y problemática actual» en Papeles de Geografía, no $23-24$, pp. 211-228 
Molina Molina, A.L.(2006) «Lorca y su término (siglos XIII-XIX)», en Estudios sobre Lorca y su comarca, Cuadernos del Grupo de Investigación Historia y Geografía del Urbanismo, $\mathrm{n}^{\circ}$ 6, Universidad de Murcia, pp. 7-50.

Morales GIL, A. (1968): «El riego con aguas de avenida en las laderas subáridas» en Papeles del Departamento de Geografia, $\mathrm{n}^{\circ}$ 1, pp. 167-183.

Morales Gil, A. (2001): Agua y territorio en la Región de Murcia, Fundación Centro de Estudios Históricos e Investigaciones Locales, Murcia, 270 pp.

Navarro Hervás, F. (1991): El sistema hidrográfico del Guadalentín, Consejería de Política Territorial, Obras Públicas y Medio Ambiente, Murcia, 256 pp.

Musso y Fontes, J. (1847): Historia de los riegos de Lorca, de los ríos Castril y Guardal o del Canal de Murcia y de los Ojos de Archivel, Murcia, 233pp.

Ordenanza para los riegos de la Ciudad de Lorca, aprobada por S.M. por Real orden de 18 de Noviembre de 1831. Incluida en Musso y Fontes, J. Historia de los riegos de Lorca (1847), Murcia, 233 pp. (Edición facsímil de Agrupación Cultural Lorquina, Lorca, 1982 con apéndices)

Ordenanza Provisional para la venta de las aguas destinadas al riego de la vega de Lorca, aprobada por R.O. de 13 de julio de 1891, (1936): Imprenta de La Tarde, Lorca, 20 pp.

Ordenanzas y privilegios de la muy noble y leal Ciudad de Lorca, (1713): Imprenta de Nicolás Prieto, Granada. Ed. facsímil en Murcia: Academia Alfonso X el Sabio, 1983. 242 pp.

PÉrez Morales, A. (2011): «Los procedimientos de evaluación y su aplicación en los Planes Generales de Ordenación Municipal como instrumentos para la mitigación del riesgo de inundación. El caso de los municipios del Sur de la Región de Murcia» Scripta Nova, Revista Electrónica de Geografía y Ciencias sociales, n ${ }^{\circ} 360$

Pocklington, R. «Acequias árabes y pre-árabes en Murcia y Lorca», (1986): en Xe Col.loqui General de la Soc. d'Onomàstica, Valencia, pp. 462-473.

Rodriguez Estrella, T.; Mancheño Jimenez, M.A. (1993): «La neotectónica de Lorca y sus alrededores en relación con la actividad actual de la falla de Alhama de Murcia. Análisis de las grietas del Túnel de Lorca y de los barrios altos de esta ciudad», V Reunión Nacional de Geología Ambiental y Ordenación del Territorio, Murcia, pp. 709-715.

Torres Fontes, J. (1977): Repartimiento de Lorca, Ayuntamiento de Murcia/Academia Alfonso X el Sabio, Murcia, 130 pp. Existe una reedición modificada de 1994.

VAllejo, J.M. Tratado sobre el movimiento y aplicaciones de las aguas. Tomo Tercero, (1833): Imprenta de D. Miguel de Burgos, Madrid, 497 pp. (El autor transcribe un informe de D. José Musso y Valiente) 